\title{
A comparative study between the effect of radio- chemotherapy versus surgery with or without postoperative radiotherapy on advanced stage hypopharyngeal carcinoma (stage III and IV); review of literature
}

\begin{abstract}
Background: The improvement of clinical outcomes for patients with hypopharyngeal squamous cell carcinoma (SCC) has been particularly challenging for head and neck surgeons and oncologists. Chemoradiotherapy (CRT) has been used for patients with advanced hypopharyngeal cancer with the aim of preserving the larynx. The reasons for the un-favorable prognosis of hypopharyngeal cancers are the strong tendency for extensive sub-mucosal spread, the early occurrence of regional lymphatic involvement, and the relatively high rate of distant spread.
\end{abstract}

Aim: This study was conducted to collect the recent data about the different modalities of management of advanced stage hypopharyngeal carcinoma (stage III and IV), and systematically review the outcomes of each modality either alone or in combination and compare their efficacy.

Methods: Search of published medical articles from 2001 till 2018, on management of advanced hypopharyngeal carcinoma either by radio- chemotherapy versus surgery alone or in combination with postoperative radiotherapy in Medline, Embase, Elsvier. Twenty-one articles fulfilled the inclusion criteria and were included in our study.

Results: Overall survival, regarding surgery group was reported in 8 studies with total 1657 patients achieved overall survival (46.23\%); While in CRT group, it was reported in 18 studies with total 2995 patients achieved overall survival (43\%). Comparative study between the 2 groups revealed decrease in overall survival rate; in CRT group; compared to surgery group; with significant statistical difference $(\mathrm{p}=0.019)$.

Conclusion: The treatment approach had a significant impact on overall survival and recurrence rate, as described in other series. Given the equivalence between these two strategies suggested in several series, definitive CRT seems to be an advantageous option as it improves organ preservation and, consequently, the functional outcome. Recent developments in chemo-radiation treatment techniques could hopefully increase tumor management and survival rates.

Keywords: advanced hypopharyngeal carcinoma management, treatment of hypopharyngeal carcinoma stage III and IV, radio-chemotherapy in advanced hypopharyngeal carcinoma management, surgery in advanced hypopharyngeal carcinoma management, radio-chemotherapy versus surgery in hypopharyngeal carcinoma, pyriform sinus, post cricoid, posterior wall carcinoma management
Volume II Issue 6 - 2019

\author{
Ossama Hamid,' Samia Ahmed,' Mohamed \\ Fathi El Rashedy, ${ }^{2}$ Amr Ossama Abdelhamid ${ }^{1,3}$ \\ 'Otorhinolaryngology Department, Faculty of Medicine, Ain \\ Shams University, Egypt \\ 'Mansoura University, Egypt \\ ${ }^{3}$ Manchester University NHS Foundation Trust, United Kingdom
}

Correspondence: Ossama Hamid, Otorhinolaryngology Department, Faculty of Medicine, Ain Shams University, Egypt, Email ossamahmid@gmail.com

Received: September 10, 2019 | Published: December 06, 2019
Abbreviations: CRT, chemoradiotherapy; SCC, squamous cell carcinoma; HSCC, hypopharyngeal squamous cell carcinoma; QOL, quality of life

\section{Introduction}

Hypopharyngeal cancer is a rare disease representing about $0.5 \%$ of all human malignancies with an incidence of less than 1 per 100 000 populations and constituting only $3-5 \%$ of all head and neck cancers. Hypopharyngeal cancers are often at an advanced stage at diagnosis and are associated with a poor prognosis. ${ }^{1-3}$ Therefore, the improvement of clinical outcomes for patients with hypopharyngeal SCC has been particularly challenging for head and neck surgeons and oncologists. CRT has been used for patients with advanced hypopharyngeal cancer with the aim of preserving the larynx. The reasons for the un-favorable prognosis of hypopharyngeal cancers are the strong tendency for extensive sub-mucosal spread, the early occurrence of regional lymphatic involvement, and the relatively high rate of distant spread. ${ }^{4}$

In the $1970 \mathrm{~s}$ and $1980 \mathrm{~s}$, surgical resection followed by radiotherapy has been the standard treatment for advanced hypopharyngeal squamous cell carcinoma (HSCC). ${ }^{5}$ This radical approach of treatment, lead to the loss of natural speech function and impairment of swallowing ability with a consequent negative impact on the quality of life, and low cure rates, reported 5-year 
survival between $20.0 \%$ and $50.0 \% .{ }^{6}$ However, since the early 1990 s, chemo- radiation (CRT) has become a valuable alternative treatment option. Due to organ preservation, it has been suggested that CRT is followed by a better long-term quality of life (QOL) than after total laryngopharynogectomy, with similar survival.

The aim: Systematically review the outcomes of surgery versus chemo-radiotherapy and compare their efficacy in advanced stage hypopharyngeal carcinoma (stage III and IV).

\section{Methods}

Target determination: Our target is to compare the effect of radio-chemotherapy versus surgery alone or in combination with postoperative radiotherapy in advanced hypopharyngeal carcinoma (stage III and IV).

Identification and location of articles: The study included the published medical articles on management of advanced hypopharyngeal carcinoma either by radio- chemotherapy versus surgery alone or in combination with postoperative radiotherapy through searching, Medline, Embase, Elsvier.

Screening and evaluation: The screening form of articles which was yielded by the search engine after blinding the author name and journal name.

\section{Screen form of the articles}

Irrelevant articles: articles that missed one or more from the above keywords.

Relevant articles: articles, which contain one or more from the above keywords, and after exclusion of repeated articles.

Included articles: These are the articles, which fulfilled the following inclusion criteria:

a. Articles in English language.

b. Number of patients reported.

c. Patients diagnosed as having advanced hypopharyngeal carcinoma (stage III and IV).

d. Used either single or multimodality (radio-chemotherapy surgery or combination of them).

e. The outcome is reported.

f. Papers published in the last 10 years.

Excluded articles: Articles which missed one or more of the above mentioned inclusion criteria.

\section{Data collection}

The data collected from the included articles included:

a. Type of study (prospective, retrospective, systematic review, meta-analysis or randomized control).

b. Number of patients treated with radio-chemotherapy.

c. Number of patients treated with surgery with or without postoperative radiotherapy

d. Outcomes and results.
Statistical analysis: Data entry, processing and statistical analysis was carried out using MedCalc ver. 15.8 (MedCalc, Ostend, Belgium). A stasistical-analysis was performed to calculate direct estimates of treatment effect for each treatment modality. According to heterogeneity of treatment effect across trials using the Istatistics; a fixed-effect model $(\mathrm{P} \geq 0.1)$ or random-effects model $(\mathrm{P}<0.1)$ was used. Generally, P-values less than $0.05(5 \%)$ was considered to be statistically significant.

$$
\begin{aligned}
& \text { P-value: level of significance } \\
& \mathrm{P}>0.05 \text { : Non-significant (NS). } \\
& \mathrm{P}<0.05 \text { : Significant (S). } \\
& \mathrm{P}<0.01 \text { : Highly significant (HS). }
\end{aligned}
$$

\section{Results}

After applying our keywords, we found 650 published articles, and after removal of duplication we found that we had 160 articles and 450 articles were excluded based on title. Then 119 articles could not be accessed or obtained as a full text, 20 articles were excluded as follows; 10 articles were review and case reports and 3 articles did not include the functional outcome, 7 articles did not correspond to the intended plan of management. Finally, 21 studies met our inclusion criteria. The demographic characteristics and clinical data in all 21studies are shown in the following tables and figures. The included articles as shown in Table 1 are published between 2001 and 2018. Regarding the type of therapeutic interventions; 2 studies used surgery technique only; 13 studies used CRT technique only, while 6 studies compared both techniques. The total number of patients in all the included studies was 10539 patients; while the biggest study was Shah and his colleagues in $2016^{1}$ as they studied 9106 patients; and the smallest study was by Suzuki G. and his colleagues in $2013^{2}$ as they studied only 19 patients.

a. Regarding surgery group, the total number of patients was (3584) patients in 8 studies.

b. Regarding CRT group, the total number of patients was (6955) patients in 19 studies. Data were divided into two groups:

1. Surgery treatment group (Surgery).

2. CRT treatment group (CRT).

Present study was done on 21 studies, which described and compared the 2 different techniques for treatment outcomes; with overall number of patients $(\mathrm{N}=10539)$ (Table 2).

a. We calculated efficacy for each technique through (overall survival and success rates).

b. We calculated safety for each technique through (Local recurrence rate, distant metastatic rate, overall recurrence, and mortality rates)

\section{Favorable treatment outcomes (surgery group) (Table 3):}

Regarding surgery group, the overall survival was reported in 8 studies with (1657) of total (3584) Patients achieved overall survival.

Success rate was reported in 7 studies with (192) of total (385) patients achieved full response to surgery. Larynx preservation rate was not reported in any study. 
A comparative study between the effect of radio-chemotherapy versus surgery with or without postoperative radiotherapy on advanced stage hypopharyngeal carcinoma (stage III and IV); review of

Table I Patients and study characteristics in all studies

\begin{tabular}{|c|c|c|c|c|}
\hline $\mathbf{N}$ & Author & Type of study & Nolpts Isurgery & Nolpts ICRT \\
\hline I & Juloori 2018 & Retrospective & NM & 54 \\
\hline 2 & Nomura 2018 & Retrospective & 33 & NM \\
\hline 3 & Chen 2018 & Retrospective & 133 & 124 \\
\hline 4 & Kim 2017 & Retrospective & 21 & 39 \\
\hline 5 & Masuda 2017 & Retrospective & 23 & 27 \\
\hline 6 & Otsuki 2017 & Retrospective & NM & 50 \\
\hline 7 & Shah 2016 & Retrospective & 3199 & 5907 \\
\hline 8 & Kim 2016 & Retrospective & NM & 34 \\
\hline 9 & Reis 2016 & Retrospective & NM & 81 \\
\hline 10 & Van 2015 & Retrospective & NM & 35 \\
\hline II & Sakashita 2015 & Retrospective & NM & 30 \\
\hline 12 & Harris 2015 & Retrospective & 28 & 48 \\
\hline 13 & Suzuki K 2013 & Retrospective & NM & 79 \\
\hline 14 & Suzuki G 2013 & Retrospective & NM & 19 \\
\hline 15 & Al Mamgani 2012 & Retrospective & NM & 176 \\
\hline 16 & Keereweer 2012 & prospective & NM & 73 \\
\hline 17 & Krstevska 2010 & Retrospective & NM & 41 \\
\hline 18 & Chang 2010 & prospective & 81 & 79 \\
\hline 19 & Iwai 2008 & Retrospective & NM & 27 \\
\hline 20 & Clark 2006 & Retrospective & 66 & NM \\
\hline 21 & Kim 200I & Retrospective & NM & 32 \\
\hline
\end{tabular}

\#Studies were arranged according to publication year. NM: not mentioned. CRT: chemo-radiotherapy

Table 2 Summary of different treatment outcomes regarding 2 management modalities

\begin{tabular}{lllll}
\hline & & Surgery+ combined & Combined 2 modalities & CRT + combined \\
\hline Studies & & $2+6$ & 6 & $13+6$ \\
patients & & 3584 & & 6955 \\
OS & Articles & 8 & 6 & 18 \\
& Patients & $1657 \backslash 3584$ & 9709 & 299516876 \\
SR & Articles & 7 & 5 & 15 \\
& Patients & 1921385 & 603 & 4361989 \\
LR & Articles & 4 & 3 & 6 \\
& Patients & 801243 & 367 & 1251313 \\
DM & Articles & 4 & 3 & 12 \\
& Patients & 591243 & 367 & 1371610 \\
OR & Articles & 2 & 2 & 9 \\
& Patients & $47 \backslash 156$ & 307 & 1981459 \\
MR & Articles & 3 & 2 & 8 \\
& Patients & 751222 & 307 & 1861544 \\
\hline
\end{tabular}


Table 3 Favorable treatment outcomes in surgery group

\begin{tabular}{|c|c|c|c|c|}
\hline \multirow{2}{*}{$\mathbf{N}$} & \multirow{2}{*}{ Author } & \multicolumn{3}{|l|}{ Favorable outcomes } \\
\hline & & Overall Survival rate & Success rate & Larynx preservation \\
\hline I & Nomura 2018 & 27 (82.2\%) & 32 (95.7\%) & NM \\
\hline 2 & Chen 2018 & 71 (53.4\%) & $63(47.6 \%)$ & NM \\
\hline 3 & Kim 2017 & 12 (59\%) & 15 (7I\%) & NM \\
\hline 4 & Masuda 2017 & $13(57 \%)$ & 17 (76\%) & NM \\
\hline 5 & Shah 2016 & 1475 (46.1\%) & NM & NM \\
\hline 6 & Harris 2015 & 19 (66.3\%) & 15 (53.6\%) & NM \\
\hline 7 & Chang 2010 & 15 (19\%) & 20 (24.2\%) & NM \\
\hline 8 & Clark 2006 & 25 (38\%) & 30 (45\%) & NM \\
\hline
\end{tabular}

Un-favorable treatment outcomes (surgery group) (Table 4):

Regarding surgery group, local recurrence rate was reported in 4 studies with (80) of total (243) patients.

Distant metastatic rate was reported in 4 studies with (59) of total (243) patients.
Overall recurrence rate was reported in 2 studies with (47) of total (165) patients.

Mortality rate was reported in 3 studies with (75) of total (222) patients died out.

Failure rate and complications rate was not reported in any study.

Table 4 Un-favorable treatment outcomes in surgery group

\begin{tabular}{llllllll}
\hline N & \multicolumn{2}{l}{ Un-favorable outcomes } & & & & \\
& & LRR & DMR & ORR & FR & CR & MR \\
\hline 1 & Chen 2018 & $38(28.2 \%)$ & $28(21.2 \%)$ & $44(33 \%)$ & NM & NM & $60(45.1 \%)$ \\
2 & Kim 2017 & $10(49.5 \%)$ & $18(85.7 \%)$ & NM & NM & NM & NM \\
3 & Masuda 2017 & $4(17.3 \%)$ & $5(21.7 \%)$ & $3(13.7 \%)$ & NM & NM & $13(56.5 \%)$ \\
4 & Clark 2006 & $28(42 \%)$ & $8(12.1 \%)$ & NM & NM & NM & $2(3 \%)$ \\
\hline
\end{tabular}

LRR, local recurrence rate; DMR, distant metastasis rate; ORR, overall recurrence rate; $F R$, failure rate; CR, complication rate; $M R$, mortality rate

\section{Favorable treatment outcomes (CRT group) (Table 5):}

Regarding CRT group, the overall survival was reported in 18 studies with (2995) of total (6876) Patients achieved overall survival.

A. Success rate was reported in 15 studies with (436) of total (989) patients achieved full response to CRT.

B. Larynx preservation rate was reported in 10 studies with (311) of total (658) patients achieved Larynx preservation.

\section{Un-favorable treatment outcomes (CRT group) (Table 6):}

1. Regarding CRT group, Local recurrence rate was reported in 6 studies with (125) of total (313) patients.

2. Distant metastasis rate was reported in 12 studies with (137) of total (610) patients.

3. Overall recurrence rate was reported in 9 studies with (198) of total (459) patients.
4. Failure rate was reported in 5 studies with (97) of total (441) of failed patients.

5. Complications rate was reported in 9 studies with (144) of total (486) patients had complications.

6. Mortality rate was reported in 8 studies with (186) of total (544) patients died out.

Comparative analysis of studies included Comparison between Surgery group and CRT group:

We started to compare the 2 groups according to different outcomes; data are shown in the following tables and figures (Table 7). Comparative study between the 2 groups revealed non-significant difference as regards the average number of patients $(\mathrm{p}>0.05)$ (Table 7). Patients who achieved favorable outcomes were pooled to evaluate efficacy by: The efficacy of each technique was measured by: 
Table 5 Favorable treatment outcomes in CRT group

\begin{tabular}{|c|c|c|c|c|}
\hline \multirow[b]{2}{*}{$\mathbf{N}$} & \multirow[b]{2}{*}{ Author } & \multicolumn{2}{|l|}{ Favorable outcomes } & \multirow[b]{2}{*}{ Larynx preservation } \\
\hline & & Overall Survival rate & Success rate & \\
\hline I & JULOORI 2018 & $23(43 \%)$ & 39 (72\%) & NM \\
\hline 2 & Chen 2018 & $40(32.3 \%)$ & $82(66.4 \%)$ & $30(24.2 \%)$ \\
\hline 3 & Kim 2017 & 13 (34\%) & 13 (34\%) & NM \\
\hline 4 & Masuda 2017 & $19(72 \%)$ & $21(76 \%)$ & $4(14 \%)$ \\
\hline 5 & Otsuki 2017 & $33(65.3 \%)$ & NM & NM \\
\hline 6 & Shah 2016 & 2587 (43.8\%) & NM & NM \\
\hline 7 & $\operatorname{Kim} 2016$ & $20(58.6 \%)$ & 17 (5 I\%) & $22(64.7 \%)$ \\
\hline 8 & Reis 2016 & 24 (29.2\%) & $10(12.5 \%)$ & NM \\
\hline 9 & Van 2015 & $9(27 \%)$ & $13(36 \%)$ & NM \\
\hline 10 & Sakashita 2015 & $26(87 \%)$ & NM & $22(74 \%)$ \\
\hline 11 & Harris 2015 & $20(41.3 \%)$ & 17 (34.5\%) & NM \\
\hline 12 & Suzuki K 2013 & NM & NM & 7 (9\%) \\
\hline 13 & Suzuki G 2013 & $10(50 \%)$ & $9(48 \%)$ & I3 (70\%) \\
\hline 14 & Al Mamgani 2012 & $65(37 \%)$ & $90(51 \%)$ & $|4|$ (80\%) \\
\hline 15 & Keereweer 2012 & 28 (38\%) & 30 (4I\%) & $53(72.7 \%)$ \\
\hline 16 & Krstevska 2010 & I 3 (32.8\%) & $12(29.3 \%)$ & NM \\
\hline 17 & Chang 2010 & $34(43.1 \%)$ & $42(53 \%)$ & NM \\
\hline 18 & Iwai 2008 & $17(63 \%)$ & 25 (93.3\%) & 8 (28.1\%) \\
\hline 19 & Kim 200I & 14 (43\%) & 16 (49.7\%) & II (34.3\%) \\
\hline
\end{tabular}

Table 6 Un-favorable treatment outcomes in CRT group

\begin{tabular}{|c|c|c|c|c|c|c|c|}
\hline \multirow{2}{*}{$\mathbf{N}$} & \multirow{2}{*}{ Author } & \multicolumn{6}{|c|}{ Un-favorable outcomes } \\
\hline & & LRR & DMR & ORR & $\mathbf{F R}$ & CR & MR \\
\hline I & Juloori 2018 & $12(22 \%)$ & $13(24 \%)$ & NM & NM & $29(53.7 \%)$ & $2(3.7 \%)$ \\
\hline 2 & Chen 2018 & $65(52.6 \%)$ & $3 \mathrm{I}(24.9 \%)$ & $65(52.4 \%)$ & $34(27.4 \%)$ & NM & $62(50 \%)$ \\
\hline 3 & Kim 2017 & $14(35.8 \%)$ & $18(46.1 \%)$ & NM & NM & NM & NM \\
\hline 4 & Masuda 2017 & $8(30 \%)$ & $8(30 \%)$ & $8(30 \%)$ & NM & $14(40 \%)$ & $6(22.2 \%)$ \\
\hline 5 & Kim 2016 & $8(23.5 \%)$ & $4(11.7 \%)$ & $12(35.3 \%)$ & NM & $4(12 \%)$ & NM \\
\hline 6 & Reis 2016 & NM & $20(25 \%)$ & NM & NM & NM & NM \\
\hline 7 & Van 2015 & I8 (50\%) & NM & NM & NM & NM & NM \\
\hline 8 & Sakashita 2015 & NM & $5(17 \%)$ & $10(33 \%)$ & $4(13 \%)$ & I (3\%) & I (3.3\%) \\
\hline 9 & Suzuki K 2013 & NM & II (I3.9\%) & $33(41.7 \%)$ & $46(58.3 \%)$ & NM & NM \\
\hline 10 & Suzuki G 2013 & NM & NM & $9(48 \%)$ & NM & $6(32 \%)$ & $6(30 \%)$ \\
\hline II & Al Mamgani 2012 & NM & NM & NM & $10(5.6 \%)$ & $28(16 \%)$ & $98(55.6 \%)$ \\
\hline 12 & Keereweer 2012 & NM & $9(12.3 \%)$ & $28(38.3 \%)$ & NM & 27 (37\%) & $2(3 \%)$ \\
\hline 13 & Krstevska 2010 & NM & $10(24.4 \%)$ & $12(29.2 \%)$ & NM & 27 (65.0\%) & $9(21 \%)$ \\
\hline 14 & Iwai 2008 & NM & $2(7.6 \%)$ & NM & NM & NM & NM \\
\hline 15 & Kim 200I & NM & $6(17.6 \%)$ & 21 (65.9\%) & $3(8 \%)$ & $8(25 \%)$ & NM \\
\hline
\end{tabular}


Table 7 Comparison between the 2 groups of studies as regards patient numbers using Mann- Whitney's U test

\begin{tabular}{llll}
\hline \multirow{2}{*}{ Variable } & CRT(19 studies) & Surgery(8 studies) & Mann-Whitney's U test \\
\cline { 2 - 3 } & Median (IQR) & Median (IQR) & P value \\
\hline Nolpatients & $48(32.5-79)$ & $49.5(25.5-107)$ & $=0.852$ \\
\hline
\end{tabular}

$\mathrm{IQR}$, inter-quartile range

\section{Risk ratio (RR)}

a. For achievement of overall survival rate.

b. For achievement of success rate.

\section{Favorable treatment outcomes:}

Comparative study between the 2 groups revealed; significant decrease in overall survival rate; in CRT group; compared to surgery group; with significant statistical difference $(\mathrm{p}=0.019)$ (Table 8).

Comparative study between the 2 groups revealed non-significant difference as regards success rate $(\mathrm{p}>0.05)$ (Figure 1).

\section{CRT vs. surgery}

6 studies reported overall survival rate simultaneously, with total number of patients $(\mathrm{N}=9709)$.

Statistical-analysis as shown in Table 9 showed that; fixedeffects model showed significant increase in overall survival rate in favor of surgery studies, while and random-effects model showed non-significant difference between the 2 groups $(\mathrm{p}=0.013, \mathrm{p}>0.05$ respectively).

Table 8 Comparison between the 2 groups of studies as regards favorable treatment outcomes by Chi square test

\begin{tabular}{|c|c|c|c|}
\hline Variable & CRT(19 studies) $\mathrm{N}=6955$ & Surgery(8 studies) $N=3584$ & $P$ value \\
\hline & & $1657(46.2 \%)^{\wedge \wedge}(8$ & \\
\hline & 2995 (43\%) (I8 studies) & & \\
\hline Overall Survival rate & & studies) & $=0.019 * *$ \\
\hline \multirow[t]{3}{*}{ Success rate } & 436 (6.2\%) (I 5 studies) & I $92(5.3 \%)^{\wedge \wedge}(7$ studies $)$ & $=0.06 \mathrm{II}$ \\
\hline & $311(4.5 \%)$ & & \\
\hline & & & ---(can't be assessed ) \\
\hline Larynx preservation & (described in 10 studies) & --- & \\
\hline
\end{tabular}

$\mathrm{N}=$ number of patients underwent this procedure. \% per column total. ${ }^{\wedge} \wedge$ total $\%<100 \%$ as outcomes was not mentioned in all studies

Table 9 Statistic-analysis of (overall survival rate) achievement on CRT vs surgery usage - Risk Ratio

\begin{tabular}{|c|c|c|c|c|c|c|c|c|c|}
\hline \multirow{2}{*}{$\mathbf{N}$} & \multirow{2}{*}{ Study } & \multirow{2}{*}{ CRT } & \multirow{2}{*}{ Surgery } & \multirow{2}{*}{$\mathbf{R R}$} & \multirow{2}{*}{$95 \% \mathrm{Cl}$} & \multirow{2}{*}{$\mathbf{Z}$} & \multirow{2}{*}{$\begin{array}{l}\mathbf{P} \\
\text { value }\end{array}$} & \multicolumn{2}{|c|}{ Weight (\%) } \\
\hline & & & & & & & & Fixed & Random \\
\hline I & Chen 2018 & $40 / 124$ & $71 / 133$ & 0.60 & 0.447 to 0.816 & & & 2.33 & 18.82 \\
\hline 2 & Kim 2017 & $13 / 39$ & $12 / 2 \mid$ & 0.58 & 0.327 to 1.040 & & & 0.63 & 12.73 \\
\hline 3 & Masuda 2017 & $19 / 27$ & $13 / 23$ & 1.24 & 0.807 to 1.922 & & & 1.12 & 15.78 \\
\hline 4 & Shah 2016 & $2587 / 5907$ & $\mid 475 / 3199$ & 0.95 & 0.906 to 0.996 & & & 93.97 & 22.74 \\
\hline 5 & Harris 2015 & $20 / 48$ & $19 / 28$ & 0.61 & 0.403 to 0.935 & & & 1.19 & 16.08 \\
\hline \multirow[t]{3}{*}{6} & Chang 2010 & $34 / 79$ & $|5 / 8|$ & 2.32 & 1.378 to 3.919 & & & 0.77 & 13.85 \\
\hline & $\mathrm{T}$ (fixed effects) & $2713 / 6224$ & $1605 / 3485$ & 0.94 & $0.90 I$ to 0.988 & -2.48 & $0.013^{*}$ & 100 & 100 \\
\hline & $\mathrm{T}$ (random effects) & $2713 / 6224$ & $1605 / 3485$ & 0.90 & 0.662 to 1.231 & 0.64 & 0.518 & 100 & 100 \\
\hline
\end{tabular}

$\mathrm{T}$, total; $\mathrm{Q}$ test for heterogeneity $=28.18$, degree of freedom $(\mathrm{DF})=5, \mathrm{p}<0.00 \mathrm{I} * *, \mathrm{I}^{2}$ (inconsistency) $=82.2 \%$ and risk ratio $(\mathrm{RR})=0.9$ 


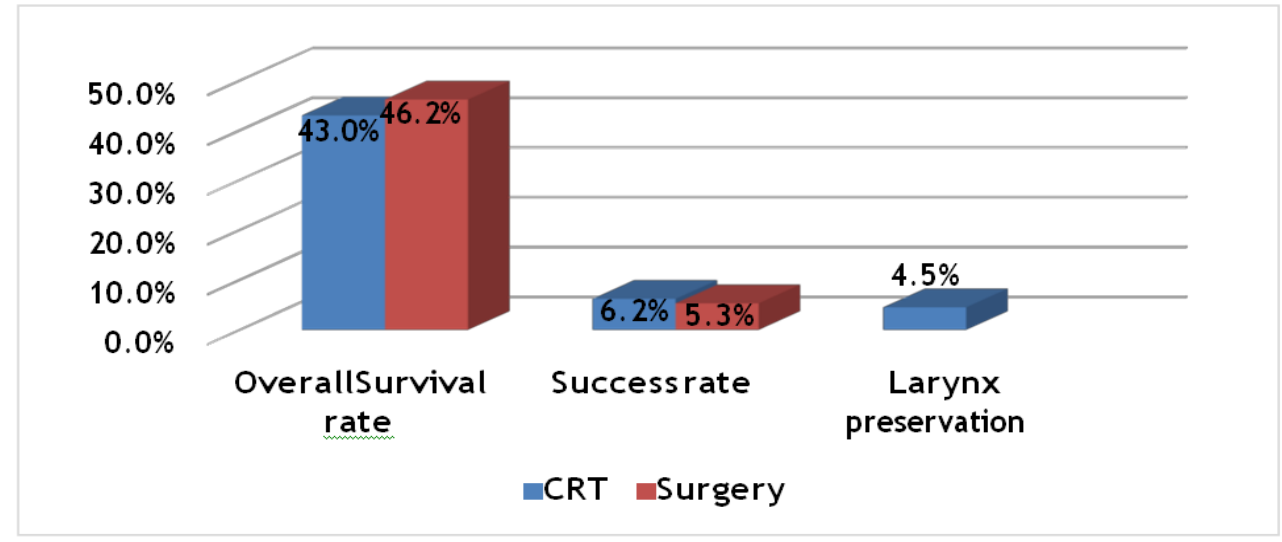

Figure I Comparison between the 2 groups of studies as regards favorable treatment outcomes.

I (inconsistency) was $82 \%$; with highly significant $\mathrm{Q}$ test for heterogeneity $(p<0.01)$; so random-effects model was chosen to assess efficacy; with overall $\mathrm{RR}=0.9$ and a $95 \% \mathrm{CI}$ for achievement of (overall survival) ranged from 0.662 to 1.231 , with non-significant difference in efficacy in the CRT group compared to surgery group (p $>0.05$ ) as shown in Table $9 \&$ Figure 2.

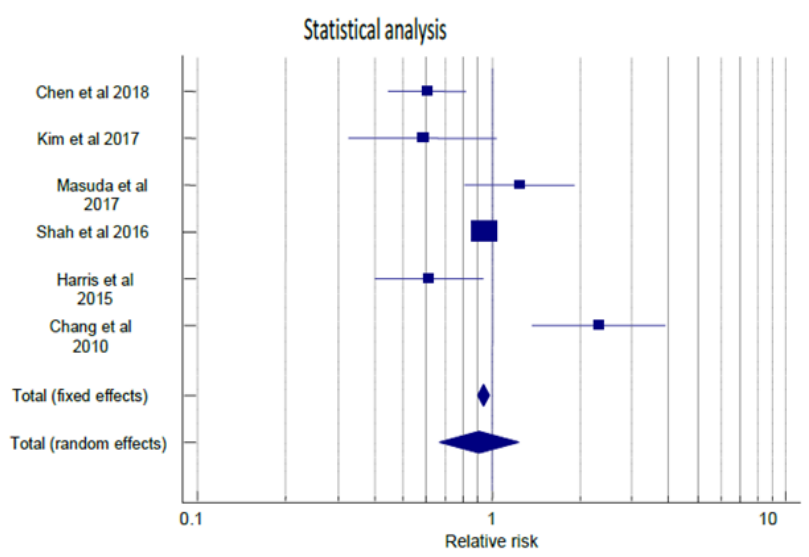

Figure 2 Forest plot of (overall survival rate) achievement on CRT vs surgery usage - Risk Ratio.

Five studies reported success rate simultaneously, with total number of patients $(\mathrm{N}=603)$.

Statistical analysis as shown in Table 10; fixed-effects model showed significant increase in success rate in favor of CRT studies, while and random-effects model showed non- significant difference between the 2 groups ( $\mathrm{p}=0.01, \mathrm{p}>0.05$ respectively).

I(inconsistency) was 85.5\%; with highly significant Q test for heterogeneity $(p<0.01)$; so random-effects model was chosen to assess efficacy; with overall $\mathrm{RR}=1.02$ and a $95 \% \mathrm{CI}$ for achievement of (success rate) ranged from 0.664 to 1.584 , with non-significant difference in efficacy in the CRT group compared to surgery group ( $\mathrm{p}$ $>0.05$ ) (Figure 3).

\section{Un-favorable treatment outcomes:}

Comparative study between the 2 groups revealed; significant increase in overall recurrence rate; in CRT group; compared to surgery group; with highly significant statistical difference $(\mathrm{p}<0.01)$ (Table 11).

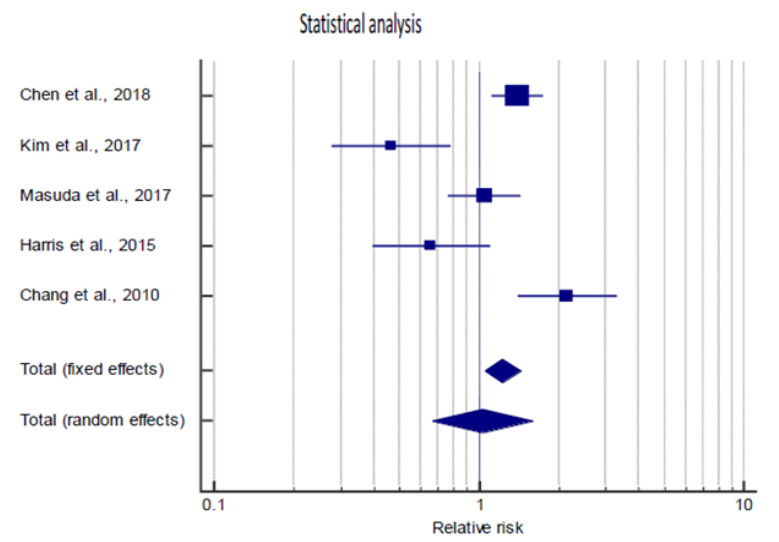

Figure 3 Forest plot of (success rate) achievement on CRT vs. surgery usage - Risk Ratio.

Comparative study between the 2 groups revealed non-significant difference as regards Local recurrence rate, distant metastatic rate, and mortality rates $(\mathrm{p}>0.05)$ (Figure 4$)$.

Patients who reached serious adverse events (SAEs) -were pooled to evaluate safety by: Safety of each technique that was measured by:

\section{Risk ratio (RR)}

a. Local recurrence rate.

b. Distant metastatic rate.

c. Overall recurrence rate.

d. Mortality rate.

We found 3 studies reported local recurrence rate simultaneously, with total number of patients $(\mathrm{N}=367)$. Statistical-analysis as shown in Table 12; showed that fixed-effects model showed significant decrease in local recurrence rate in favor of surgery studies, while and random-effects model showed nonsignificant difference between the 2 groups $(p=0.001, p>0.05$ respectively). 


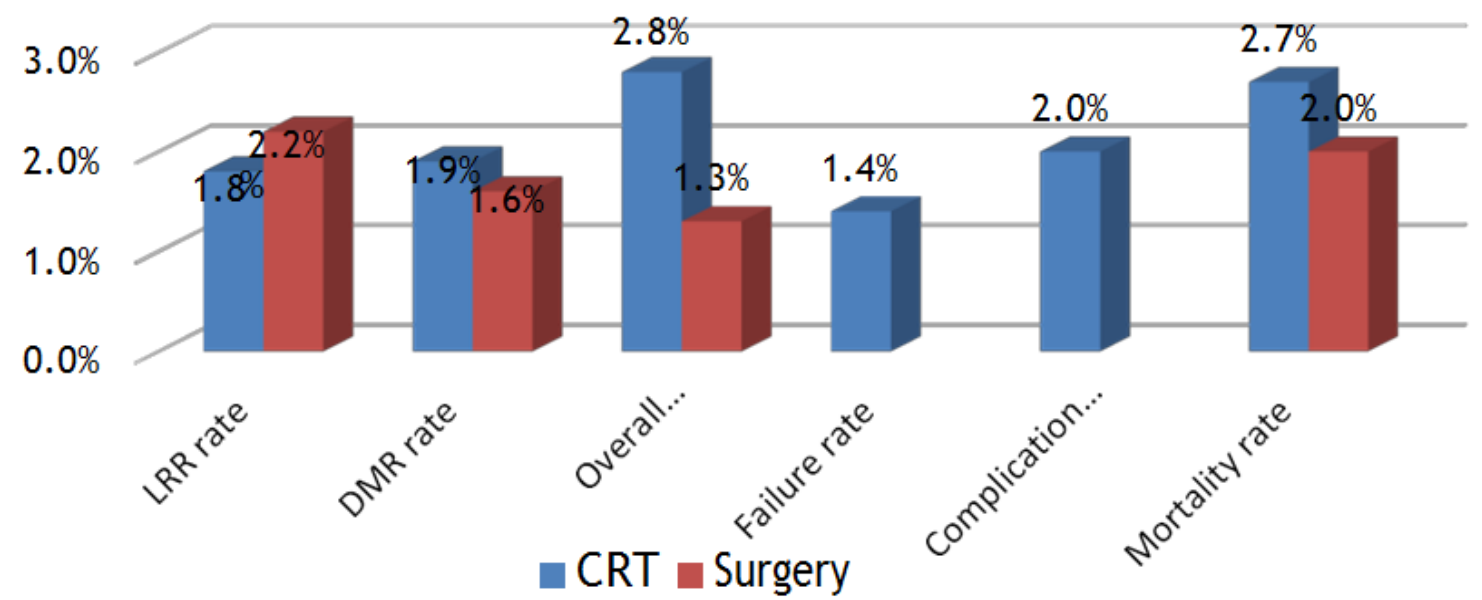

Figure 4 Comparison between the 2 groups of studies as regards un-favorable treatment outcomes.

Table IO Statistical-analysis of (success rate) achievement on CRT vs. surgery usage - Risk Ratio

\begin{tabular}{|c|c|c|c|c|c|c|c|c|c|}
\hline \multirow{2}{*}{$\mathbf{N}$} & \multirow{2}{*}{ Study } & \multirow{2}{*}{ CRT } & \multirow{2}{*}{ Surgery } & \multirow{2}{*}{$\mathbf{R} \mathbf{R}$} & \multirow{2}{*}{$95 \% \mathrm{Cl}$} & \multirow{2}{*}{$\mathbf{Z}$} & \multirow{2}{*}{$P$ value } & \multicolumn{2}{|c|}{ Weight (\%) } \\
\hline & & & & & & & & Fixed & Random \\
\hline I & Chen 2018 & $82 / 124$ & $63 / 133$ & 1.39 & I.I2I to 1.738 & & & 47.7I & 22.84 \\
\hline 2 & Kim 2017 & $13 / 39$ & $|5 / 2|$ & 0.46 & 0.278 to 0.785 & & & 8.47 & $18.0 \mid$ \\
\hline 3 & Masuda 2017 & $21 / 27$ & $17 / 23$ & 1.05 & 0.767 to 1.443 & & & 22.97 & 21.50 \\
\hline 4 & Harris 2015 & $17 / 48$ & $15 / 28$ & 0.66 & 0.395 to 1.106 & & & 8.64 & 18.10 \\
\hline \multirow[t]{6}{*}{5} & Chang 2010 & $42 / 79$ & $20 / 8 I$ & 2.15 & 1.396 to 3.320 & & & 12.20 & 19.55 \\
\hline & & $|75 / 3|$ & $130 / 28$ & & & & & & \\
\hline & $\mathrm{T}$ (fixed effects) & & & 1.22 & 1.050 to 1.430 & 2.583 & $0.01 *$ & 100 & 100 \\
\hline & & $\begin{array}{l}7 \\
|75 / 3|\end{array}$ & $\begin{array}{l}6 \\
130 / 28\end{array}$ & & & & & & \\
\hline & $\mathrm{T}$ (random effects) & & & 1.02 & 0.664 to 1.584 & 0.112 & 0.911 & 100 & 100 \\
\hline & & 7 & 6 & & & & & & \\
\hline
\end{tabular}

$Q$ test for heterogeneity $=27.54$, degree of freedom $(D F)=4, p<0.00 I^{* *}, I^{2}$ (inconsistency) $=85.5 \%$ and risk ratio $(R R)=1.02$

Table I I Comparison between the 2 groups of studies as regards un-favorable treatment outcomes using Chi square test

\begin{tabular}{|c|c|c|c|}
\hline Variable & CRT ( 19 studies) N=6955 & Surgery( 8 studies) $N=3584$ & $P$ value \\
\hline LRR & I25 (I.8\%) (6 studies) & $80(2.2 \%)^{\wedge \wedge}(4$ studies $)$ & $=0.125$ \\
\hline DMR & I 37 (I.9\%) (I2 studies) & $59(1.6 \%)^{\wedge \wedge}(4$ studies $)$ & $=0.244$ \\
\hline ORR & I 98 (2.8\%) (9 studies) & $47(1.3 \%)^{\wedge \wedge}(2$ studies $)$ & $<0.0001 * *$ \\
\hline FR & 97 (I.4\%) (5 studies) & --- & ---(can't be assessed ) \\
\hline$C R$ & I44 (2\%) (9 studies) & --- & ---(can't be assessed ) \\
\hline MR & I86 (2.7\%) (8 studies) & $75(2 \%)^{\wedge \wedge}(3$ studies $)$ & $=0.068$ \\
\hline
\end{tabular}

$\mathrm{N}=$ number of patients underwent this procedure. \% per column total. ${ }^{\wedge}$ total $_{\%}<100 \%$ as outcomes was not mentioned in all studies 
I (inconsistency) was 68.8\%; with significant $\mathrm{Q}$ test for heterogeneity $(\mathrm{p}=0.04)$; so random- effects model was chosen to assess safety; with overall $\mathrm{RR}=1.33$ and a $95 \% \mathrm{CI}$ for (LRR) ranged from 0.707 to 2.510 , with non-significant difference in safety in the CRT group compared to surgery group $(\mathrm{p}>0.05)$ as shown in Table 12 \& Figure 5
We found 3 studies reported DMR rate simultaneously, with total number of patients $(\mathrm{N}=367)$.

Statistical-analysis as shown in Table 13; showed that fixed and random-effects models showed non-significant difference in DMR between the 2 groups $(\mathrm{p}>$ 0.05 respectively)

Table I 2 statistical-analysis of (LRR) on CRT vs surgery usage - Risk Ratio

\begin{tabular}{|c|c|c|c|c|c|c|c|c|c|}
\hline \multirow{2}{*}{$\mathbf{N}$} & \multirow{2}{*}{ Study } & \multirow{2}{*}{ CRT } & \multirow{2}{*}{ Surger y } & \multirow{2}{*}{$\mathbf{R R}$} & \multirow{2}{*}{$95 \% \mathrm{Cl}$} & \multirow{2}{*}{$\mathbf{Z}$} & \multirow{2}{*}{$P$ value } & \multicolumn{2}{|c|}{ Weight (\%) } \\
\hline & & & & & & & & Fixed & Random \\
\hline \multirow[t]{2}{*}{ I } & Chen 2018 & $65 / 124$ & $38 / 133$ & 1.83 & 1.337 to 2.518 & & & 73.82 & 44.87 \\
\hline & & & & & 0.408 to & & & & \\
\hline \multirow[t]{2}{*}{2} & Kim20I7 & $14 / 39$ & $10 / 2 \mid$ & 0.75 & & & & 19.64 & 34.27 \\
\hline & & & & & 1.393 & & & & \\
\hline \multirow[t]{5}{*}{3} & Masuda 2017 & $8 / 27$ & $4 / 23$ & 1.70 & 0.588 to 4.935 & & & 6.55 & 20.86 \\
\hline & & & & & 1.194 to & & & & \\
\hline & $\mathrm{T}$ (fixed effects) & $87 / 190$ & $52 / 177$ & 1.56 & & 3.25 & $0.001 * *$ & 100 & 100 \\
\hline & & & & & $\begin{array}{l}2.048 \\
0.707 \text { to }\end{array}$ & & & & \\
\hline & $\mathrm{T}$ (random effects) & $87 / 190$ & $52 / 177$ & 1.33 & 2.510 & 0.886 & 0.376 & 100 & 100 \\
\hline
\end{tabular}

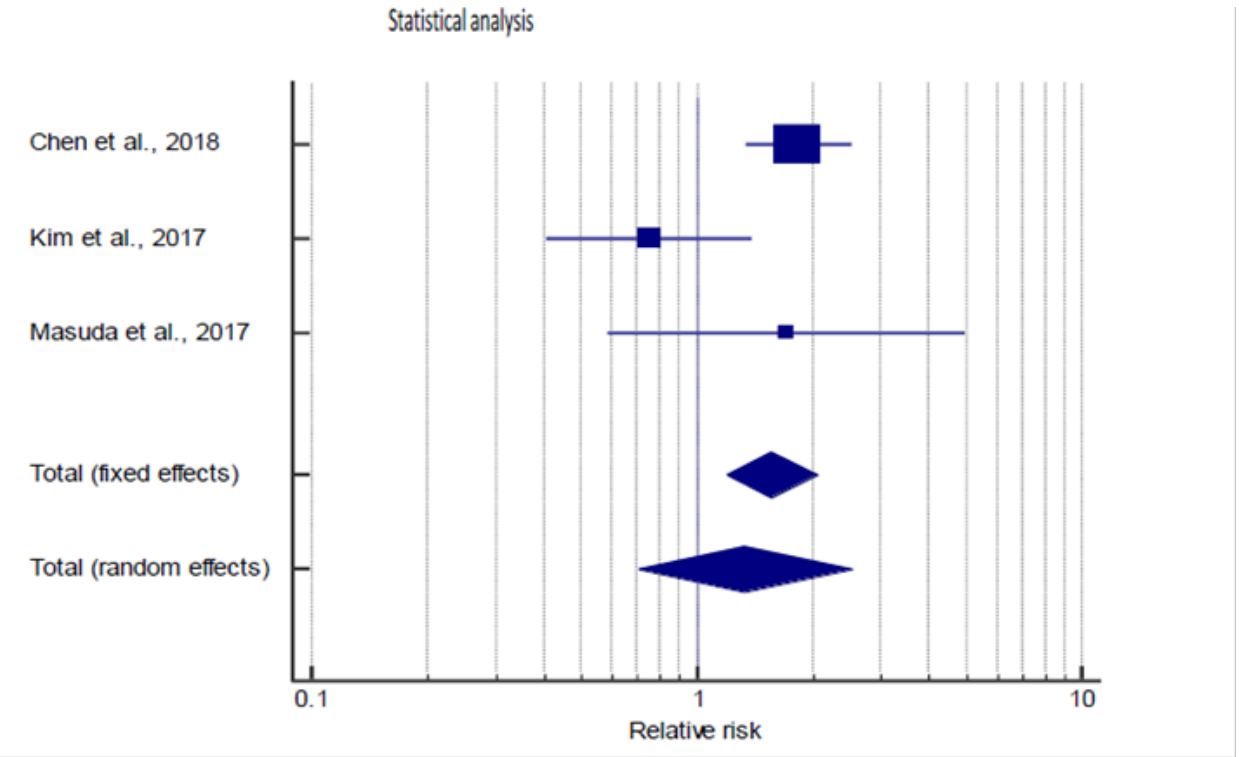

Figure 5 Forest plot of (LRR) on CRT vs. surgery usage - Risk Ratio.

I (inconsistency) was 79.3\%; with highly significant Q test for heterogeneity $(\mathrm{p}=0.0079)$; so random-effects model was chosen to assess safety; with overall $\mathrm{RR}=0.9$ and a $95 \% \mathrm{CI}$ for $(\mathrm{DMR})$ ranged from 0.453 to 1.788 , with non-significant difference in safety in the CRT group compared to surgery group $(\mathrm{p}>0.05)$ (Figure 6).

Two studies reported overall recurrence rate simultaneously, with total number of patients $(\mathrm{N}=307)$.

Statistical-analysis as shown in Table 14; fixed and random-effects model showed highly significant decrease in overall recurrence rate in favor of surgery studies ( $\mathrm{p}=0.001$ respectively).
I(inconsistency) was $0 \%$; with non-significant $Q$ test for heterogeneity ( $\mathrm{p}>0.05)$; so fixed- effects model was chosen to assess safety; with overall $\mathrm{RR}=1.63$ and a $95 \%$ CI for (overall recurrence rate) ranged from 1.225 to 2.177 , with highly significant decrease in overall recurrence and increase in safety in favor of surgery studies ( $\mathrm{p}$ $=0.001$ ) (Figure 7).

Two studies reported mortality rate simultaneously, with total number of patients $(\mathrm{N}=307)$.

Statistical-analysis as shown in Table 15; fixed and random-effects models showed non- significant difference in mortality rate between the 2 groups ( $\mathrm{p}>0.05$ respectively). 
Table I 3 Statistical-analysis of (Distant metastatic rate) on CRT vs surgery usage - Risk Ratio

\begin{tabular}{|c|c|c|c|c|c|c|c|c|c|}
\hline \multirow{2}{*}{$\mathbf{N}$} & \multirow{2}{*}{ Study } & \multirow{2}{*}{ CRT } & \multirow{2}{*}{ Surger y } & \multirow{2}{*}{$\mathbf{R} \mathbf{R}$} & \multirow{2}{*}{$95 \% \mathrm{Cl}$} & \multirow{2}{*}{$\mathbf{Z}$} & \multirow{2}{*}{ P value } & \multicolumn{2}{|c|}{ Weight (\%) } \\
\hline & & & & & & & & Fixed & Random \\
\hline I & Chen 2018 & $31 / 124$ & $28 / 133$ & 1.18 & 0.758 to 1.860 & & & 38.49 & 37.36 \\
\hline 2 & Kim 2017 & $18 / 39$ & $18 / 21$ & 0.53 & 0.368 to 0.788 & & & 53.27 & 39.09 \\
\hline \multirow[t]{3}{*}{3} & Masuda 2017 & $8 / 27$ & $5 / 23$ & 1.36 & 0.517 to 3.592 & & & 8.25 & 23.56 \\
\hline & $\mathrm{T}$ (fixed effects) & $57 / 190$ & $51 / 177$ & 0.93 & 0.693 to 1.254 & -0.463 & 0.643 & 100 & 100 \\
\hline & $\mathrm{T}$ (random effects) & $57 / 190$ & $51 / 177$ & 0.90 & 0.453 to 1.788 & -0.300 & 0.765 & 100 & 100 \\
\hline
\end{tabular}

Table I4 Statistical-analysis of (overall recurrence rate) on CRT vs. surgery usage - Risk Ratio

\begin{tabular}{|c|c|c|c|c|c|c|c|c|c|}
\hline \multirow[b]{2}{*}{$\mathbf{N}$} & \multirow[b]{2}{*}{ Study } & \multirow[b]{2}{*}{ CRT } & \multirow{2}{*}{ Surger y } & \multirow[b]{2}{*}{$\mathbf{R R}$} & \multirow[b]{2}{*}{$95 \% \mathrm{Cl}$} & \multirow[b]{2}{*}{$\mathbf{Z}$} & \multirow[b]{2}{*}{$P$ value } & \multicolumn{2}{|c|}{ Weight (\%) } \\
\hline & & & & & & & & Fixed & Random \\
\hline & & $65 / 12$ & & & & & & 94.3 & \\
\hline \multirow[t]{2}{*}{ I } & Chen 2018 & & $44 / 133$ & 1.58 & 1.181 to 2.126 & & & & 94.37 \\
\hline & & 4 & & & & & & 7 & \\
\hline \multirow[t]{4}{*}{2} & Masuda 2017 & $8 / 27$ & $3 / 23$ & 2.27 & & & & 5.63 & 5.63 \\
\hline & & $73 / 15$ & & & 7.578 & & & & \\
\hline & $T$ (fixed effects) & $\begin{array}{l}1 \\
73 / 15\end{array}$ & $47 / 156$ & 1.63 & $\begin{array}{l}1.225 \text { to } 2.177 \\
1.215 \text { to }\end{array}$ & 3.345 & $0.001 * *$ & 100 & 100 \\
\hline & $\mathrm{T}$ (random effects) & I & $47 / 156$ & 1.61 & 2.152 & 3.296 & $0.00 I^{* *}$ & 100 & 100 \\
\hline
\end{tabular}

$Q$ test for heterogeneity $=0.32$, degree of freedom $(D F)=I, P=0.566, I^{2_{2}}$ (inconsistency) $=0 \%$ and risk ratio $($ RR) $=I .63$

Table 15 Statistical-analysis of (mortality rate) on CRT vs. surgery usage - Risk Ratio

\begin{tabular}{|c|c|c|c|c|c|c|c|c|c|}
\hline \multirow{2}{*}{$\mathbf{N}$} & \multirow{2}{*}{ Study } & \multirow{2}{*}{ CRT } & \multirow{2}{*}{ Surgery } & \multirow{2}{*}{$\mathbf{R} \mathbf{R}$} & \multirow{2}{*}{$95 \% \mathrm{Cl}$} & \multirow{2}{*}{$\mathbf{Z}$} & \multirow{2}{*}{$P$ value } & \multicolumn{2}{|c|}{ Weight (\%) } \\
\hline & & & & & & & & Fixed & Random \\
\hline & & & & & 0.857 to & & & & \\
\hline \multirow[t]{2}{*}{1} & Chen 2018 & $62 / 124$ & $60 / 133$ & 1.10 & & & & 90.45 & 56.70 \\
\hline & & & & & 1.433 & & & & \\
\hline \multirow[t]{5}{*}{2} & Masuda 2017 & $6 / 27$ & $13 / 23$ & 0.39 & 0.178 to 0.868 & & & 9.55 & 43.30 \\
\hline & & & & & 0.760 to & & & & \\
\hline & T (fixed effects) & $68 / 151$ & $73 / 156$ & 0.96 & & -0.257 & 0.797 & 100 & 100 \\
\hline & & & & & 1.234 & & & & \\
\hline & $\mathrm{T}$ (random effects) & $68 / 151$ & $73 / 156$ & 0.70 & 0.257 to 1.949 & -0.669 & 0.503 & 100 & 100 \\
\hline
\end{tabular}

$Q$ test for heterogeneity $=6.03$, degree of freedom $(D F)=I, P=0.014 *, I^{2}$ (inconsistency) $=83.4 \%$ and risk ratio $(R R)=0.7$

I(inconsistency) was $83.4 \%$; with significant $Q$ test for heterogeneity $(\mathrm{p}=0.014)$; so random- effects model was chosen to assess safety; with overall $\mathrm{RR}=0.7$ and a $95 \% \mathrm{CI}$ for (mortality rate) ranged from 0.257 to 1.949 , with non-significant difference in safety in the CRT group compared to surgery group $(\mathrm{p}>0.05)$ (Figure 8). 


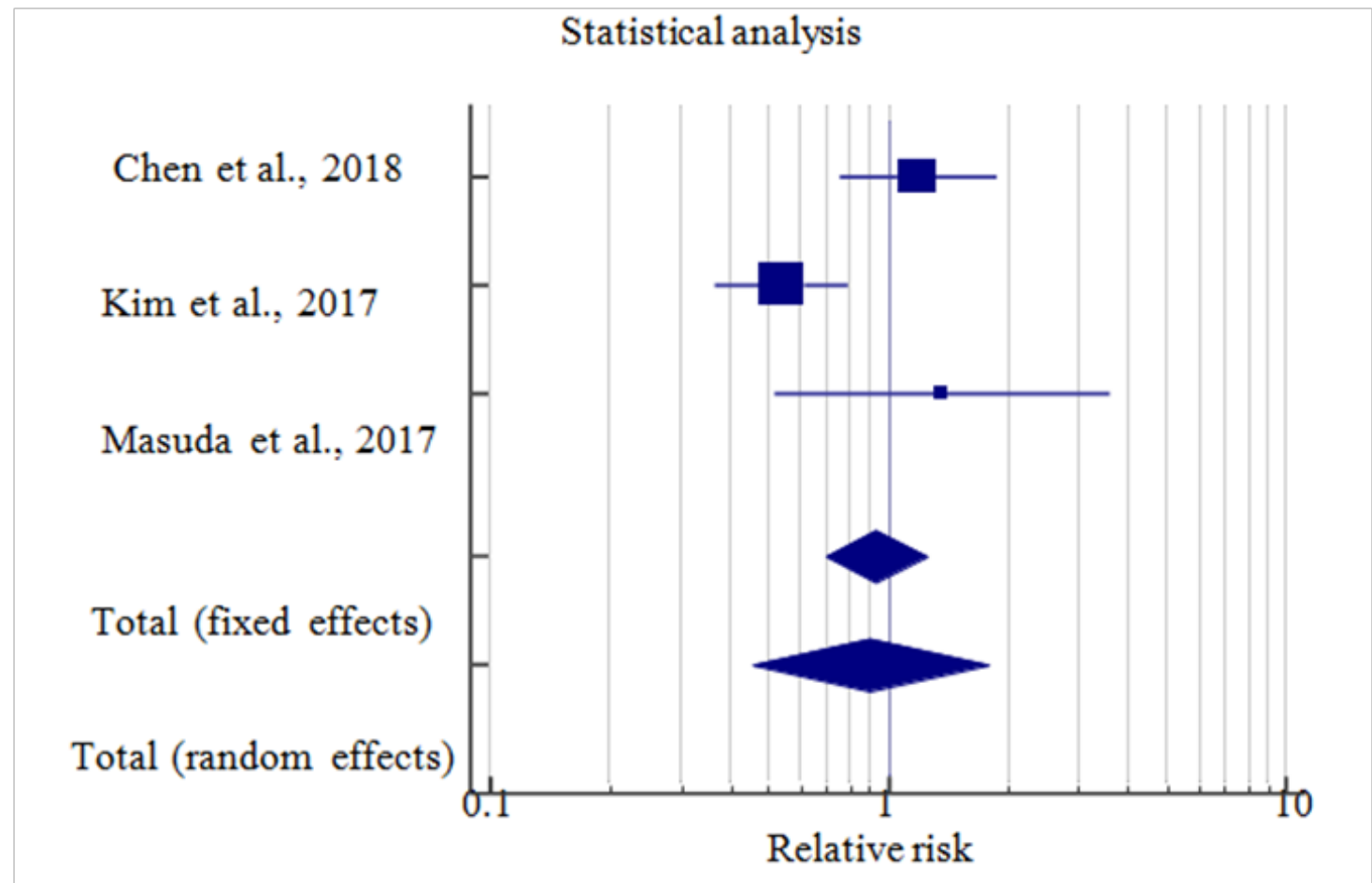

Figure 6 Forest plot of (DMR) on CRT vs. surgery usage - Risk Ratio.

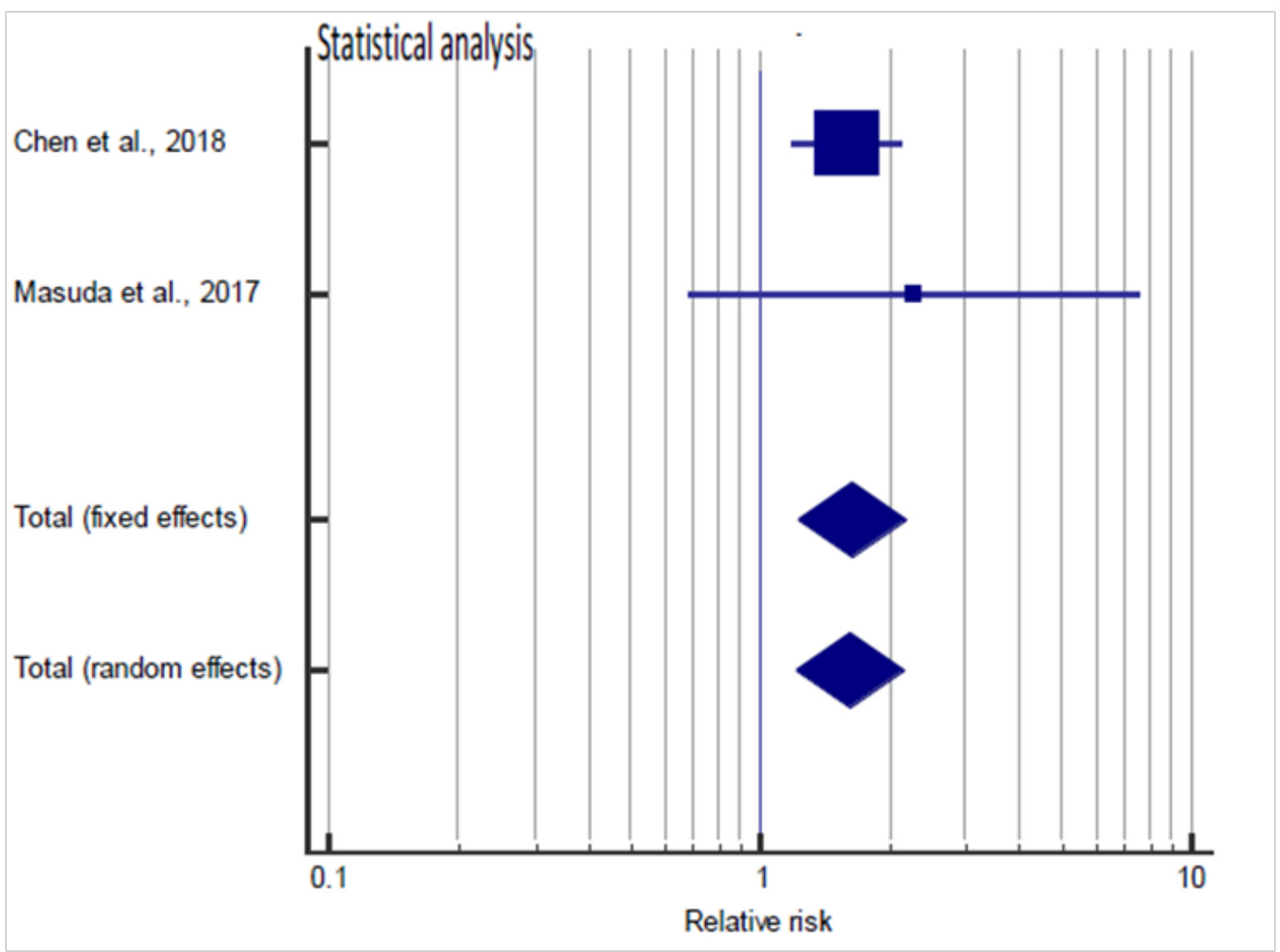

Figure 7 Forest plot of (overall recurrence rate) on CRT vs. surgery usage - Risk Ratio. 


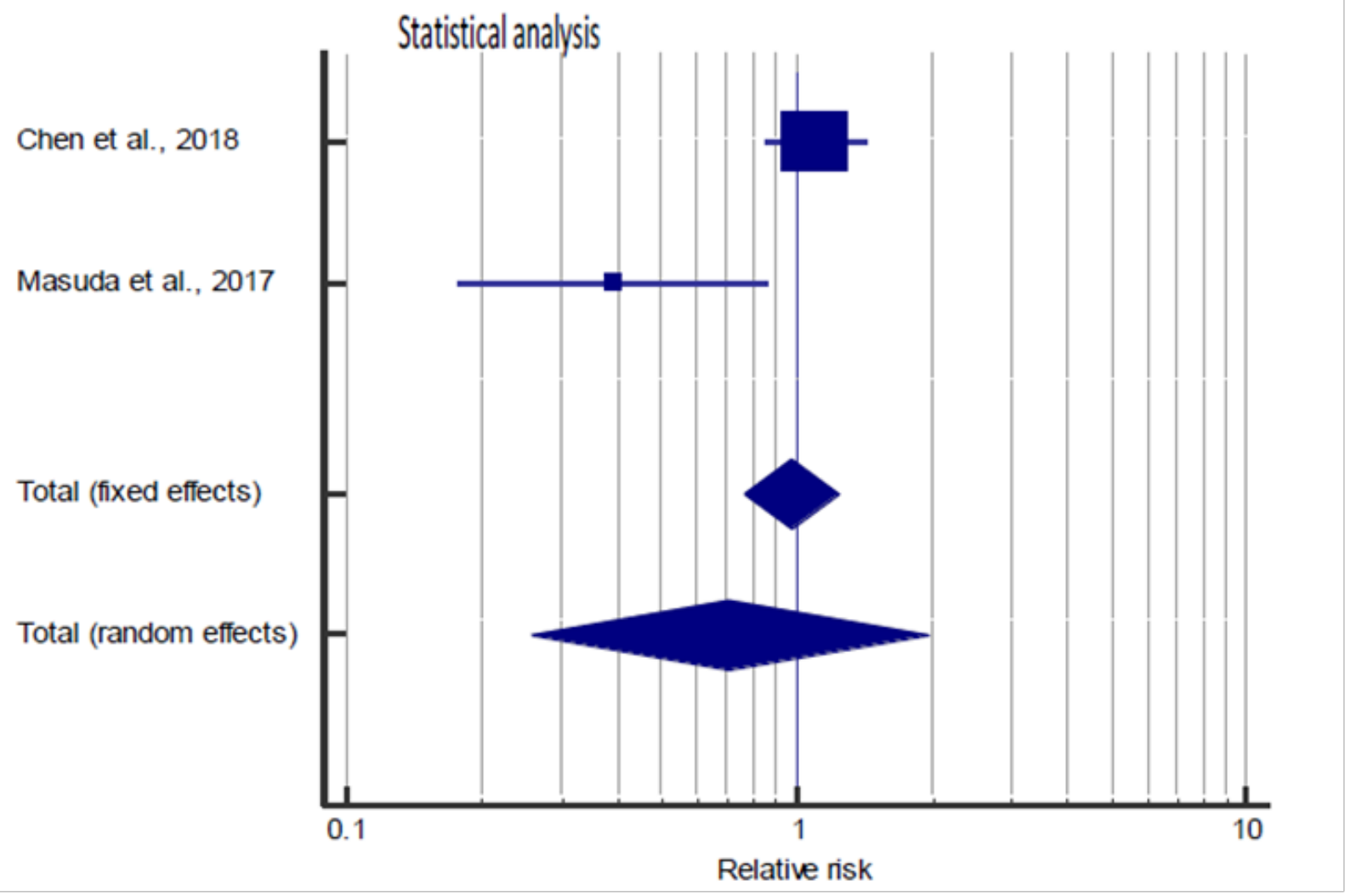

Figure 8 Forest plot of (mortality rate) on CRT vs. surgery usage - Risk Ratio.

\section{Discussion}

Hypopharyngeal cancer is a rare disease representing about $0.5 \%$ of all human malignancies with an incidence of less than 1 per 100 000 populations and constituting only $3-5 \%$ of all head and neck cancers. Hypopharyngeal cancers are often at an advanced stage at diagnosis and are associated with a poor prognosis. ${ }^{3}$ Therefore, the improvement of clinical outcomes for patients with hypopharyngeal SCC has been particularly challenging for head and neck surgeons and oncologists. Chemo-radiotherapy has been used for patients with advanced hypopharyngeal cancer with the aim of preserving the larynx. The reasons for the un-favorable prognosis of hypopharyngeal cancers are the strong tendency for extensive sub-mucosal spread, the early occurrence of regional lymphatic involvement, and the relatively high rate of distant spread. ${ }^{4}$ In the 1970s and 1980s, surgical resection followed by radiotherapy has been the standard treatment for advanced hypopharyngeal squamous cell carcinoma (HSCC). ${ }^{5}$ This radical approach of treatment, leads to the loss of natural speech function and impairment of swallowing ability with a consequent negative impact on the quality of life, and low cure rates, with reported 5-year survival between $20.0 \%$ and $50.0 \% .{ }^{6}$ However, since the early 1990 s, chemo-radiation (CRT) has become a valuable alternative treatment option. Due to organ preservation, it has been suggested that CRT is followed by a better long-term quality of life than after total laryngopharyngectomy (TLE), with similar survival. ${ }^{7}$

The Aim of our study is to collect the recent data about the different modalities of management of advanced stage hypopharyngeal carcinoma (stage III and IV), and systematically review the outcomes of each modality and compare the efficacy of them. We found 21 studies that fulfilled all inclusion criteria. The included studies published between 2001-2018. Regarding the type of therapeutic interventions; 2 studies used surgery technique only; 13 studies used CRT technique only, while 6 studies compared both techniques. To the best of our knowledge, this is the largest systematic review in this subject. The total number of patients in all the included studies was 10539 patients; while the biggest study was by Shah et al., ${ }^{1}$ who studied 9106 patients; and the smallest study was by Suzuki G et al., ${ }^{2}$ who studied only 19 patients. We divided the included studies into
A. Surgery treatment group (Surgery).
B. CRT treatment group (CRT).

With comparing of the different outcomes:

The total number of patients in surgery group was 3584 patients $(34 \%)$ in 8 studies, While CRT group; it was 6955patients $(66 \%)$ in 19 studies.

Age, sex, and tumor stage have all been established as prognostic factors affecting survival in patients with HP SCC.

Overall survival, regarding surgery group was reported in 8 studies with total 1657 patients achieved overall survival (46.23\%); While in CRT group, it was reported in 18 studies with total 2995patients 
achieved overall survival (43\%). Comparative study between the 2 groups revealed decrease in overall survival rate; in CRT group; compared to surgery group; with significant statistical difference $(\mathrm{p}=0.019)$. According to Taha and his colleagues in 2013 there was no survival difference between the organ preservation intended therapy and radical surgery groups. Patients who received concurrent radiochemotherapy had a better chance of survival with a preserved larynx compared with patients who underwent surgery. ${ }^{8}$ It is a well-known fact that postoperative RT or CRT improves tumor control in head and neck cancer patients with high-risk features. However, the cost of using adjuvant RT or CRT to improve disease control and survival may be substantial, namely increased treatment-related toxicities and prolongation of the total treatment time. In unsuccessful organ preservation attempts, failures in function preservation may result from either toxicity from aggressive CRT, extensive tumor infiltration into the organ at the time of diagnosis, or from progression of disease. ${ }^{7}$ In the present study Success rate was reported in 7 studies with total 192patients achieved full control by surgical management (5.35\%). While as reported in 15 studies with total 436patients achieved full response on CRT $(6.26 \%)$. Comparative study between the 2 groups revealed non- significant difference as regards success rate $(\mathrm{p}>0.05)$.

A study by Brasilino de Carvalho in $1998^{\circ}$ has analyzed data of 170 patients with laryngeal and hypopharyngeal cancer and reported that 5-year disease free survival of patients without cervical metastases is significantly higher than that in patients with cervical metastases $(56.8 \%$ vs. $10.2 \%, \mathrm{p}<0.0001)$.

Patients who achieved favorable outcomes were pooled to evaluate efficacy and risk ratio via:

a. Achievement of overall survival rate.

b. Achievement of success rate.

Six studies reported overall survival rate simultaneously, with total number of patients $(\mathrm{N}=9709)$.

Statistical-analysis study showed that; fixed-effects model showed significant increase in overall survival rate in favor of surgery studies, while random-effects model showed non- significant difference between the 2 groups ( $\mathrm{p}=0.013, \mathrm{p}>0.05$ respectively). I2 (inconsistency) was $82 \%$; with highly significant $Q$ test for heterogeneity $(p<0.01)$. So random-effects model was chosen to assess efficacy; with overall $\mathrm{RR}=0.9$ and a $95 \% \mathrm{CI}$ for achievement of (overall survival) ranged from 0.662 to 1.231 , with non-significant difference in efficacy in the CRT group compared to surgery group ( $p>0.05)$. Kim and others considered that nonsurgical therapy (induction chemotherapy plus RT) is an effective strategy to achieve organ preservation without compromising the survival of locally advanced hypopharyngeal carcinoma patients. ${ }^{6}$ Five studies reported success rate simultaneously, with total number of patients $(\mathrm{N}=603)$. Statistical-analysis study showed that; fixed-effects model showed significant increase in success rate in favor of CRT studies, while random-effects model showed non-significant difference between the 2 groups ( $\mathrm{p}=0.01, \mathrm{p}>0.05$ respectively). I2 (inconsistency) was $85.5 \%$; with highly significant $\mathrm{Q}$ test for heterogeneity $(\mathrm{p}<0.01)$; so random-effects model was chosen to assess efficacy; with overall $\mathrm{RR}=1.02$ and a $95 \% \mathrm{CI}$ for achievement of (success rate) ranged from 0.664 to 1.584 , with non-significant difference in efficacy in the CRT group compared to surgery group $(\mathrm{p}>0.05)$.
A matched-pair analysis by Rades and his colleagues in 2011, compared definitive radio-chemotherapy to surgery followed by radio (chemo) therapy as treatment strategies for T3/4 larynx and hypopharynx cancer. Overall survival rates were $67 \%$ and $63 \%$, respectively $(\mathrm{p}=0.95)$ these did not result in significantly worse overall survival. ${ }^{10}$ The better results in this study may be due to the hidden selection biases that could not be excluded due to the retrospective nature of the study. Overall recurrence rate reported in 2 studies presenting surgical management outcomes with total 47patients had overall recurrence (1.3\%). in 9 studies presenting CRT total 198patients had overall recurrence rate $(2.84 \%)$. Comparative study between the 2 groups revealed; highly significant increase in overall recurrence rate in CRT group compared to surgery group with highly significant statistical difference $(p<0.01)$. According to Vaidya and his colleagues in 2001 patients who underwent surgical resection 18 out of 24 patients showed recurrences for those who had cervical metastases with extra-capsular nodal spread involving distant sites, especially to the lung. ${ }^{11}$ Local recurrence rate was reported in 4 studies regarding surgery group with total 80patients had Local recurrence rate $(2.23 \%)$, otherwise CRT group, LRR was reported in 6 studies with total 125patients had local recurrence rate (1.79\%). Distant metastatic rate was reported in 4 studies discussing surgical management of advanced hypopharyngeal carcinoma with total 59 patients had distant metastatic rate (1.64\%). in 12 studies dealing with CRT total 137 patients had distant metastatic rate $(1.96 \%)$.

Mortality rate of surgery was reported in 3 studies with 75 patients with disease specific mortality (2\%), but 8 studies presenting CRT with 186patients died from the disease (2.67\%). Comparative study between the 2 groups revealed non-significant difference as regard local recurrence rate, distant metastatic rate, and mortality rates $(\mathrm{p}>0.05)$. A significant indicator of recurrence was margin status. It is known that inadequate resection can lead to increased likelihood of disease recurrence and poorer odds of survival for patients. ${ }^{12}$ Ravasz and his colleagues in 1991 has shown that loco-regional recurrence observed in $20 \%$ of 80 head and neck cancer patients is correlated with tumor positive margins. ${ }^{13}$ For Rades and his colleagues radio-chemotherapy did not result in significantly worse outcomes in terms of loco-regional management and metastasis-free survival. Two-year loco-regional control rates were $75 \%$ for surgery plus radio-chemotherapy and $66 \%$ for radio-chemotherapy $(\mathrm{p}=0.39)$. Metastases- free survival rates were $76 \%$ and $77 \%$, respectively $(\mathrm{p}=0.76) .{ }^{10}$ The rarity of this disease, and the time required for data collection explains in part the absence of a randomized trial undertaken to evaluate the role-played by CRT in the treatment of advanced hypopharyngeal cancer. Additionally, patients longing for preserving their larynx probably will not be willing to participate in a randomized clinical trial offering a $50 \%$ chance of larynx preservation, as a non-surgical option is available. ${ }^{14}$

In favor of CRT as reported in 10 studies 311 patients achieved larynx preservation $(4.47 \%)$, failure rate was reported in 5 studies with 97 patients whose treatment failed (1.39\%).

While mean 9 studies reported complications rate with 144patients (2\%) had complications. None of larynx preservation, failure rate or complications rate were reported regarding surgery group. Considering that larynx preservation is such an important issue, despite the absence of prospective data, definitive radio-chemotherapy does not seem to be inferior to surgery plus radiotherapy for locally advanced hypopharynx cancer, and allows for a significant higher larynx preservation rate. ${ }^{14}$ 
Also, Study by Rades and his colleagues: radio-chemotherapy resulted in a considerably higher rate of larynx preservation as compared with the primary surgical approach. ${ }^{10}$ Patients who reached serious adverse events were pooled to assess safety by assessing:

a. Overall recurrence rate.

b. Local recurrence rate.

c. Distant metastatic rate.

d. Mortality rate.

Three studies reported LRR simultaneously, with total number of patients $(\mathrm{N}=367)$. Statistical-analysis study showed that; fixed-effects model showed significant decrease in local recurrence rate in favor of surgery studies, while random-effects model showed non-significant difference between the 2 groups ( $\mathrm{p}=0.001, \mathrm{p}>0.05$ respectively).

I2 (inconsistency) was 68.8\%; with significant $\mathrm{Q}$ test for heterogeneity $(\mathrm{p}=0.04)$. So random-effects model was chosen to assess safety; with overall recurrence rate $=1.33$ and a $95 \% \mathrm{CI}$ for (Local recurrence rate) ranged from 0.707 to 2.510, with nonsignificant difference in safety in the CRT group compared to surgery group $(\mathrm{p}>0.05)$

Three studies reported distant metastatic rate simultaneously, with total number of patients $(\mathrm{N}=367)$.

Statistical-analysis study showed that; fixed and random-effects models showed non- significant difference in distant metastatic rate between the 2 groups ( $\mathrm{p}>0.05$ respectively).

I2 (inconsistency) was 79.3\% with highly significant Q test for heterogeneity $(p=0.0079)$; so random-effects model was chosen to assess safety; with overall recurrence rate $=0.9$ and a $95 \% \mathrm{CI}$ for (Distant metastatic rate) ranged from 0.453 to 1.788 , with nonsignificant difference in safety in the CRT group compared to surgery group ( $\mathrm{p}>0.05)$.

Two studies reported overall recurrence rate simultaneously, with total number of patients $(\mathrm{N}=307)$.

Statistical-analysis study showed that; fixed and random-effects models showed highly significant decrease in overall recurrence rate in favor of surgery studies ( $\mathrm{p}=0.001$ respectively). I2 (inconsistency) was $0 \%$ with non-significant $\mathrm{Q}$ test for heterogeneity $(\mathrm{p}>0.05)$; so fixed- effects model was chosen to assess safety; with overall recurrence rate $=1.63$ and $95 \%$ CI for (overall recurrence rate) ranged from 1.225 to 2.177 , with highly significant decrease in overall recurrence and increase in safety in favor of surgery studies $(\mathrm{p}=0.001)$. Two studies reported mortality rate simultaneously, with total number of patients $(\mathrm{N}=307)$. Statistical-analysis study showed that; fixed and random-effects models showed non- significant difference in mortality rate between the 2 groups ( $>0.05$ respectively). I2 (inconsistency) was $83.4 \%$; with significant $\mathrm{Q}$ test for heterogeneity $(p=0.014)$; so random-effects model was chosen to assess safety; with overall recurrence rate $=0.7$ and a $95 \% \mathrm{CI}$ for (mortality rate) ranged from 0.257 to 1.949 , with non-significant difference in safety in the CRT group compared to surgery group $(\mathrm{p}>0.05)$. Urba and colleagues reported $79 \%$ of patients with grade 3 and 4 toxicity treated with CRT for carcinoma in the hypopharynx or base of the tongue. ${ }^{15}$ Moreover, the functional sparing of the laryngo-pharynx is not always granted with such protocols. Treatment related toxicity; the need for permanent gastrostomy tube placement and overall preservation of laryngo-esophageal function remains low. ${ }^{16}$ In the advanced stage setting, CRT is frequently proposed for patients in whom functional status has not been irreversibly compromised. Otherwise, a primary surgical approach followed by postoperative RT is typically adopted. The shift to organ preservation protocols worldwide, are mainly due to improved laryngo-pharyngeal preservation in such cases. However, one should not miss that these protocols have high toxicity rate and need intensive patient care and monitoring by experienced multidisciplinary teamwork. ${ }^{4}$

\section{Conclusions}

Hypopharyngeal cancer is a distinct clinical entity of head and neck cancer with a relatively poor prognosis. In summary, the survival outcomes for locally advanced hypopharynx cancer in the present study are consistent with other studies in the literature. The treatment approach had a significant impact on OS and RR, as described in other series. Given the equivalence between these two strategies suggested in several series, definitive CRT seems to be an advantageous option as it improves organ preservation and, consequently, the functional outcome. Recent developments in chemo-radiation treatment techniques could hopefully increase tumor management and survival rates.

\section{Acknowledgments}

None.

\section{Conflict of interests}

The authors declare that there is no conflict of interests regarding the publication of this paper.

\section{Funding}

None.

\section{References}

1. Shah, BA, Qureshi MM, Mak KS, et al. Primary Surgical Versus Primary Radiation Therapeutic Approaches for Locally Advanced Hypopharyngeal Carcinoma: An Analysis from the National Cancer Data Base (NCDB). International Journal of Radiation Oncology Biology Physics. 2016;96(2):E348-E349.

2. Suzuki G, Ogo E, Abe T, Hayabuchi N, et al. Non-surgica multimodality treatment for locally advanced (T3-4) hypopharyngeal cancer: the impact of pre-treatment hemoglobin level. Anticancer research. 2013;33(12):5561-5565.

3. Cooper JS, Pajak TF, Forastiere AA, et al. Postoperative concurrent radiotherapy and chemotherapy for high-risk squamous-cell carcinoma of the head and neck. N Engl J Med. 2004;350(19):1937-1944.

4. Tai SK, Yang MH, Wang LW, et al. Chemoradiotherapy laryngeal preservation for advanced hypopharyngeal cancer. Jpn J Clin Oncol. 2008;38(8):521-527.

5. Keereweer S, Kerrebijn JD, Al-Mamgani A, et al. Chemoradiation for advanced hypopharyngeal carcinoma: a retrospective study on efficacy, morbidity and quality of life. Eur Arch Otorhinolaryngol. 2012;269(3):939-946.

6. Kim S, Wu HG, Heo DS, et al. Advanced hypopharyngeal carcinoma treatment results according to treatment modalities. Head Neck. 2001;23(9):713-717. 
7. Lefebvre JL, Rolland F, Tesselaar M, et al. Phase 3 randomized trial on larynx preservation comparing sequential vs alternating chemotherapy and radiotherapy. J Natl Cancer Inst. 2009;101(3):142-152.

8. Taha MS, Tamer S Sobhya, Ossama M Hamid, et al. Concurren radiochemotherapy versus surgery followed by radiotherapy for hypopharyngeal carcinoma: A single-center study. Egyptian Journal of Ear, Nose, Throat and Allied Sciences. 2013;14(3):175-183.

9. De Carvalho MB. Quantitative analysis of the extent of extracapsular invasion and its prognostic significance: a prospective study of 170 cases of carcinoma of the larynx and hypopharynx. Head Neck. 1998;20(1):16-21

10. Rades D, Schroeder U, Bajrovic A, et al. Radiochemotherapy versus surgery plus radio (chemo) therapy for stage T3/T4 larynx and hypopharynx cancer-results of a matched-pair analysis. Eur J Cancer. 2011;47(18):2729-2734.

11. Vaidya AM, Petruzzelli GJ, Clark J, et al. Patterns of spread in recurrent head and neck squamous cell carcinoma. Otolaryngology-Head and Neck Surgery. 2001;125(4):393-396.
12. Beitler JJ, Smith RV, Silver CE, et al. Close or positive margins after surgical resection for the head and neck cancer patient: the addition of brachytherapy improves local control. Int J Radiat Oncol Biol Phys. 1998;40(2):313-317.

13. Laszlo A Ravasz, Pieter J Slootweg, Gert J Hordijk, et al. The status of the resection margin as a prognostic factor in the treatment of head and neck carcinoma. Journal of Cranio-Maxillofacial Surgery. 1991;19(7):314-318.

14. Jeremic B, Milicic B, Dagovic A, et al. Radiation therapy with or without concurrent low-dose daily chemotherapy in locally advanced, nonmetastatic squamous cell carcinoma of the head and neck. $J$ Clin Oncol. 2004;22(17):3540-3548.

15. Urba SG1, Moon J, Giri PG, et al. Organ preservation for advanced resectable cancer of the base of tongue and hypopharynx: a Southwest Oncology Group Trial. J Clin Oncol. 2005;23(1):88-95.

16. Rudat V, Ahmet-Osman S, Schramm O, et al. Definitive radiotherapy versus postoperative radiotherapy of patients with oro-and hypopharyngeal cancer: impact of prognostic factors. $J$ Oncol. 2012 